\title{
DIFERENTES ABORDAGENS SOBRE O TEMA SAÚDE E AMBIENTE: DESAFIOS PARA O ENSINO DE CIÊNCIAS*
}

\section{Different approaches to health and environment: challenges for teaching science}

Francine Pinhão ${ }^{1}$. Isabel Martins ${ }^{2}$

\begin{abstract}
Resumo: Neste trabalho traçamos um breve histórico sobre a relação entre os temas saúde e ambiente, e apresentamos uma revisão de literatura nacional que mapeia os principais campos onde a temática vem sendo pesquisada. A partir de tal discussão, refletimos mais especificamente sobre o modo pelo qual estes temas têm sido inseridos na escola, e advogamos a favor de um enfoque que vincule a saúde ambiental à saúde humana, buscando ampliar as possibilidades da construção de um ensino de ciências que lide com abordagens multidimensionais. Por fim, sinalizamos para a necessidade de investimentos na formação inicial e continuada de profissionais na área de ciências, professores e bacharéis, a fim de impulsionar práticas interdisciplinares.
\end{abstract}

Palavras-chave: Saúde e ambiente. Ensino de ciências. Educação em saúde. Educação ambiental.

Abstract: In this paper we outline a brief history of the relationship between health and environment issues through review of Brazilian literature in different fields of knowledge. From this discussion, we reflect more specifically on the ways through which these topics have been dealt with in schools and advocate for an approach that foregrounds relationships between environmental health and human health, with a view to expanding the possibilities of science education to deal with multidimensional approaches. Finally, we point to the necessity of investments in initial and continuing education for both science teachers and scientific researchers, to foster interdisciplinary practices.

Keywords: Health and environment. Science education. Health education. Environmental education.

\footnotetext{
* Trabalho desenvolvido no Programa de Pós-graduação Educação em Ciências e Saúde, Universidade Federal do Rio de Janeiro.

${ }^{1}$ Departamento de Educação, Instituto de Educação de Angra dos Reis, Universidade Federal Fluminense (UFF). Avenida dos Trabalhadores, 179, Jacuecanga, Polo Universitário Jair Travassos. Angra dos Reis, RJ, Brasil.23.900-000.pinhaofl@hotmail.com

${ }^{2}$ Núcleo de Tecnologia Educacional para a Saúde (NUTES), UFRJ. Rio de Janeiro, RJ, Brasil.
} 


\section{A integração saúde e ambiente: breve histórico, relações e suas implicações para a educação em ciências}

A relação entre a saúde humana e o meio ambiente vem sendo estabelecida desde os primórdios da humanidade e se consolidou no ocidente por meio dos escritos hipocráticos (TAMBELLINI; CÂMARA, 1998; PIGNATTTI, 2003; RIBEIRO, 2004). Desde então, esta relação vem sendo repensada de acordo com as novas perspectivas sobre o conceito de saúde e de meio ambiente. Tais conceitos são desenvolvidos em distintos âmbitos disciplinares e em contextos sócio-históricos distintos e, por isso, correspondem a problemas emergentes de épocas determinadas.

Minayo et al. (1998) afirmam que, no Brasil, a preocupação com a relação entre os problemas ambientais e as características socioeconômicas se tornam relevantes para a saúde coletiva no início do século XX, através do trabalho pioneiro de Oswaldo Cruz e dos sanitaristas que o seguiram. Neste artigo, a autora e seus colaboradores caracterizam três paradigmas básicos presentes nos estudos sobre a interface entre problemas ambientais e de saúde, a saber: o biomédico, com origens na parasitologia clássica; o da relação saneamento e ambiente, com origens no saneamento clássico; e o da medicina social, que tem suas origens nos anos 1970 e que se constituiu em referência para o campo da saúde coletiva.

Pignatti (2003), ao fazer um histórico sobre as perspectivas teóricas ocidentais que tratam a relação saúde e ambiente, mostra que o entendimento atual sobre a integração dos campos tem fundamentação tanto nos estudos do campo da Saúde Pública quanto da Ecologia Humana. Ambos os campos começam a se fortalecer teoricamente, e a se aproximar, sob uma perspectiva mais complexa a partir dos anos 1970, quando os efeitos da industrialização e da urbanização passaram a impor agravos à saúde humana. Antes disso, uma série de concepções sobre o tema já haviam sido levantadas, porém a partir de perspectivas vinculadas a momentos sócio-históricos diferentes do que vivemos atualmente.

A importância dos processos socioeconômicos também é trazida por Freitas e Porto (2006) ao traçarem um histórico sobre a interface saúde e ambiente, segundo a noção de sustentabilidade. Estes autores apontam três grandes processos socioeconômicos que estão interconectados e são essenciais para a compreensão de como o processo de constituição da sociedade vem agravando os problemas de saúde humana e ambiental. O primeiro tem a ver com "processos demográficos de crescimento e mobilidade populacional" (FREITAS; PORTO, 2006, p. 39); o segundo está relacionado com o aumento e intensificação das trocas comerciais; e, por fim, o terceiro processo diz respeito às diferentes formas pelas quais as sociedades têm se apropriado dos recursos naturais.

Segundo estes autores (FREITAS; PORTO, 2006), a agricultura e a domesticação dos animais foi o primeiro grande marco de uma sequência de transformações na relação que estabelecemos com os recursos da natureza. A segunda grande transformação foi o estabelecimento de cidades-estado, impérios e reinos da Mesopotâmia, o que pode ser interpretado como resultado do controle da produção de alimento e capacidade de armazenamento e troca. Outra transformação envolve a expansão territorial e o estabelecimento de grandes redes comerciais. Este processo de invasão territorial e trocas comerciais foi acentuado com o surgimento das grandes rotas de navegação. Mais recentemente, nossas relações com os recursos naturais passaram a ser mediadas pelo processo de industrialização. Este processo, iniciado no 
Diferentes abordagens sobre o tema saúde ...

século XIX na França, gerou grandes migrações das zonas rurais para as zonas urbanas e o aumento descontrolado da população que, em geral, vivia submetida a precárias condições de higiene e trabalho (FREITAS; PORTO, 2006).

Durante as décadas de 1960 e 1970, os efeitos da industrialização e urbanização começam a ser publicados em forma de pesquisas e relatórios que chamavam atenção para a situação de crise ambiental que se configurava. Além disso, passado o quadro de morbimortalidade, o campo da saúde passou a lidar com problemas relacionados com os hábitos de vida e a interação dos indivíduos com o ambiente social e natural (ASSIS, 1992). Novas condições da vida social - tais como a instalação de fábricas, o aumento do número de automóveis e a nova organização do trabalho orientada pela perspectiva capitalista - trouxeram novas questões para o campo da saúde, as quais estavam intimamente ligadas com o ambiente.

$\mathrm{Na}$ tentativa de tratar especificamente de problemas de saúde e ambiente, foi criada uma subárea da saúde pública, nomeada de Saúde Ambiental, especificamente voltada para o controle de fatores ambientais potencialmente prejudiciais à saúde. O estabelecimento desta área como campo disciplinar fundamenta-se, inicialmente, nas bases teóricas da epidemiologia clássica, voltada para aspectos causais. Uma versão mais recente da saúde ambiental está mais intimamente ligada às Ciências Sociais, preocupando-se com os princípios éticos de justiça ambiental, envolvendo dimensões dificilmente quantificáveis, tais como: o contexto social, econômico e cultural. Esta nova versão dialoga com o ideário veiculado pelo campo da saúde do trabalhador, o qual associa as questões de saúde e ambiente ao modo de produção desenvolvido na sociedade moderna (RIBEIRO, 2004).

No campo da pesquisa acadêmica, houve mobilização para promover a aproximação entre os temas saúde e ambiente, sobretudo a partir de novas teorias e abordagens voltadas para a luta da redemocratização do país. Por meio deste movimento, originalmente desenvolvido no campo das Ciências Sociais e Humanas, a saúde passa a tratar o ambiente vinculado à noção de coletivo e não mais por meio da categoria "população", originada na epidemiologia. Assim, inicia-se o desenvolvimento de uma nova saúde pública, a saúde coletiva (TAMBELLINI; CÂMARA, 1998). No contexto da saúde coletiva, os aspectos sociais, ao invés de serem quantificados, passaram a ser qualificados (AUGUSTO et al., 2003).

A partir da década de 1980, o delineamento dos diferentes conceitos e práticas vinculados às questões de saúde e ambiente - bem como a aproximação entre eles - passou a ser muito influenciado por conferências e encontros internacionais onde foram estabelecidos objetivos e selados compromissos, com a finalidade de atender a uma demanda considerada, antes de tudo, como social (PELICIONI, 2000).

Durante a II Conferência Internacional de Promoção da Saúde, realizada em Adelaide em 1988, o principal tema foi a criação de políticas públicas saudáveis para a viabilização de ambientes favoráveis à saúde. Já a III Conferência Internacional de Promoção da Saúde, realizada em Sundsvall em 1991, teve como principal foco a discussão sobre a interdependência entre a saúde e o meio ambiente, partindo do entendimento de ambos numa perspectiva multidimensional, que ultrapassa o enfoque biológico dado aos assuntos referentes a estes temas (PELICIONI, 2000).

A maior conferência já realizada pela Organização das Nações Unidas (ONU), Conferência das Nações Unidas sobre o Meio Ambiente e o Desenvolvimento (CNUMAD), conhecida também como ECO-92 ou RIO-92, consolidou a aprovação de vários documentos, 
entre eles, a Agenda 21, conhecida como "o documento da esperança", um programa de ações para viabilizar o desenvolvimento sustentável, pretendendo a diminuição das desigualdades sociais e o estabelecimento de uma justiça ambiental (PELICIONI, 2000).

Por meio deste percurso histórico, acreditamos ser possível identificar uma variedade de formas de conceber as relações saúde e ambiente, mesmo que muitas delas apresentem sobreposições. Destacamos, em particular, aquelas que investem na possibilidade de estabelecer relações causais entre saúde e ambiente, seja numa perspectiva unicausal ou multicausal. A primeira pode ser identificada em trabalhos que fazem referência ao controle microbiológico, na qual os problemas de saúde e ambiente são atribuídos a uma causa biológica específica e passível de controle. Já a multicausalidade pode ser caracterizada pela ampliação do espectro de fatores intervenientes, que passam a incluir causas biológicas, sociais e culturais. A abordagem multicausal pode ser exemplificada pelo conceito de "história natural da doença", que, ao assumir o ambiente biológico e social como algo externo ao homem, acaba atribuindo característica objetiva aos aspectos subjetivos da vida social. Uma versão de abordagem multicausal diferente desta pode se dar no contexto da saúde coletiva, onde o sentido de monitorar tem a ver não apenas com a quantificação, mas com a qualificação dos contextos envolvidos no processo de causalidade (AUGUSTO et al., 2003). Este tipo de abordagem, apesar de se preocupar mais especificamente com aspectos da vida social segundo uma lógica dinâmica, valorizando os contextos socioambientais, não difere epistemologicamente das demais, uma vez que também é pautada no modelo da causalidade.

Augusto et al. (2003), ao apresentarem o resultado das reflexões sobre a inserção da Saúde Ambiental na Saúde Coletiva, promovidas no Grupo de Trabalho (GT) "Saúde e Ambiente" da Associação Brasileira de Saúde Coletiva (Abrasco), o fazem por meio de três eixos: a identificação do campo teórico-conceitual em saúde e ambiente; a política de saúde e ambiente; o caminho metodológico. Ao apresentarem o primeiro eixo, advogam em favor de uma virada conceitual que priorize a relação saúde e ambiente por meio dos contextos relevantes para cada tipo de problema específico, e não das causas. Assim, buscam uma virada de paradigma de intervenção por meio de perguntas do tipo "como" e não do tipo "por que".

No entanto, acreditamos que, apesar de estes autores advogarem em favor de uma virada de paradigma, torna-se difícil determinar quando o ambiente deixa de ser causa e passa a ser contexto na relação que estabelece com a saúde, pois, mesmo quando se busca o "como", procuram-se fundamentalmente as causas pelas quais um evento ocorreu. Sendo assim, não consideramos que esta mudança de foco possa ser concebida como uma mudança epistemológica ou de paradigma.

Freitas et al. (2007), ao discutirem uma abordagem ecossistêmica para a saúde, identificam, atualmente, duas vertentes que se baseiam no enfoque ecossistêmico da saúde. Uma é mais identificada com a mensuração de sinais e sintomas presentes no ecossistema que afetam a saúde humana, e se baseia, fundamentalmente, na construção de informações científicas para a tomada de decisão. Já a segunda busca soluções para os problemas nos ecossistemas que se relacionam com o contexto específico e as consequências das transformações deste ecossistema para a comunidade local.

Diante dessa discussão inicial, pouco identificada com a educação escolar, podemos nos questionar sobre qual seria a relação desta discussão com a escola. Tendo em vista que a escola é convidada a refletir sobre as demandas sociais, o debate sobre o meio ambiente e a 
Diferentes abordagens sobre o tema saúde ...

saúde sempre estiveram presentes neste espaço, sobretudo na disciplina escolar ciências, como temas promotores de diálogo com as questões sociais. Tanto são tratados como elementos de contextualização, que, nas duas últimas décadas, as reformas da educação em nosso país incluíram tais temáticas sob a política da transversalidade. Além disso, outros setores do governo, além do Ministério da Educação, também atribuem à escola o papel de promover debate sobre tais problemas. Por exemplo, o Ministério da Saúde julga importante, para o desenvolvimento das políticas em prol da Promoção da Saúde, a aproximação destas com o sistema escolar. No informe técnico "A promoção da saúde no contexto escolar" (BRASIL, 2002), afirma que a possibilidade de a escola tornar estas propostas concretas está situada na sua função social e política, o que possibilita a transformação da sociedade através do exercício da cidadania. Também deixa claro que: "Uma estratégia (de promoção da saúde) direcionada para essa população (juventude brasileira de 10 a 24 anos) que pretenda ter alcance significativo precisa estar associada à escola, onde grande parte dela se encontra" (BRASIL, 2002, p. 534).

O documento em questão aponta a necessidade de formação adequada dos professores para o exercício de estratégias desse tipo e ressalta a importância da criação de estratégias intersetoriais, como, por exemplo, a elaboração dos Parâmetros Curriculares Nacionais (PCN) em Ação Saúde. Nesse sentido, estes documentos se constituem num entrelaçamento de discursos dos campos da Educação, da Saúde, da Ecologia que, a princípio, poderiam ser pensados como desconectados.

Diante disso, cabe o questionamento sobre como a escola, mais especificamente o ensino de ciências está implicado com as demandas relacionadas à saúde e ao ambiente. Sendo assim, propomos, abaixo, uma discussão sobre a relação desta temática com a disciplina escolar ciências.

\section{As relações saúde e ambiente no âmbito da disciplina escolar Ciências no Brasil}

As disciplinas escolares, como é o caso da disciplina ciências, se constituem por meio de processos distintos daqueles que estruturam as disciplinas acadêmicas, pois suas origens epistemológicas e sócio-históricas são distintas. Assim sendo, não se pode contar a história das disciplinas escolares por meio da história das disciplinas acadêmicas. A disciplina Ciências, mais especificamente, tem sua origem na própria escola, uma vez que, diferentemente das demais disciplinas ligadas às Ciências Naturais, tais como a Física, a Química ou a Biologia, não possui um único campo acadêmico correspondente (LOPES, 2000). Macedo e Lopes (2002) chamam atenção para o fato de a disciplina Ciências ter sido criada como forma de integrar diferentes disciplinas científicas, mas que, atualmente, apresenta os conteúdos de forma desconectada.

De toda forma, um projeto que vise à integração de diferentes saberes no espaço escolar possui natureza distinta daqueles voltados para a pesquisa acadêmica. Apesar disso, podemos buscar inspiração na fala de Fourez (1995) sobre a interdisciplinaridade no âmbito da pesquisa científica, para pensá-la no espaço escolar, guardadas as finalidades particulares em cada espaço específico. Para este autor, a interdisciplinaridade se torna algo potencialmente interessante, sobretudo quando tratamos de temas tão complexos quanto os da área da saúde. 
Uma vez constatado o fato de que os problemas existentes não podem ser respondidos por meio de apenas uma perspectiva, cada vez mais vêm surgindo propostas de trabalho interdisciplinar. Entretanto, muitas delas não chegam a desenvolver um trabalho, de fato, integrado ou, quando o fazem, orientam a noção de interdisciplinaridade por um caminho equivocado. Fourez (1995) afirma que existem duas maneiras distintas de se trabalhar. A primeira surge a partir da crença na possibilidade de se elaborar uma superciência que dê conta de abranger todos os aspectos envolvidos em um determinado problema. Uma união deste tipo, muitas vezes, resulta na criação de uma nova disciplina, a qual passa a tratar as questões do cotidiano seguindo seus próprios paradigmas e, invariavelmente, não atinge a complexidade dos problemas cotidianos. Já a segunda não se compromete com a tarefa de elaborar um conhecimento para além das disciplinas particulares, mas busca respostas a partir das especificidades de diferentes disciplinas. Dessa forma, a interdisciplinaridade é concebida como prática, e não como a possibilidade de elaboração de uma superciência. Logo, "o objetivo não será criar uma disciplina científica, nem um discurso universal, mas resolver um problema concreto" (FOUREZ, 1995, p. 136) por meio da mobilização de diferentes conhecimentos disciplinares. Em princípio, não podemos considerar que a disciplina escolar ciências se encaixe em nenhum desses modelos de interdisciplinaridade. No entanto, por analogia, podemos considerar que a disciplina escolar ciências foi baseada em um projeto no qual se pretendiam organizar diversas disciplinas científicas em uma mesma disciplina, como se uma única disciplina escolar pudesse dar conta do conhecimento básico de todas as disciplinas acadêmicas relacionadas às Ciências Naturais. Nesse sentido, não se operou uma real articulação entre os diferentes conhecimentos científicos como forma de responder às demandas sociais, mas, sim, se constituiu uma disciplina com características próprias, sem um correspondente acadêmico, e que se sustenta pela relação que guarda com os conteúdos da biologia.

Ainda de acordo com Fourez (1995), não podemos atribuir o fracasso da interdisciplinaridade à existência de um currículo disciplinar, mas à inexistência de relação entre as disciplinas escolares. Para este autor, a interdisciplinaridade não é um tipo de conhecimento, mas sim uma prática política. Assim sendo, não se operam mudanças efetivas na educação se não forem repensadas as bases das práticas pedagógicas.

De acordo com os PCN, uma possibilidade de desenvolver um trabalho integrado e que dê conta das questões sociais está na transversalidade. Este documento alega que as "questões urgentes que devem necessariamente ser tratadas, como a violência, a saúde, o uso de recursos naturais, os preconceitos, não têm sido contempladas por essas áreas" (BRASIL, 1997, p. 23).

Esta afirmação, de acordo com Macedo (1998), torna-se a principal justificativa para a inclusão dos temas transversais, e reafirma a ideia de que um currículo estruturado em disciplinas não viabiliza o desenvolvimento da função social da escola. Segundo a mesma autora, não basta operar modificações estruturais no currículo com o intuito de atender as demandas sociais, pois o que deve ser contestado, antes da estrutura, é o tipo de conhecimento que está sendo privilegiado. Sobre a mesma questão, Lopes (2002) argumenta que não é a simples substituição de um currículo disciplinar por um currículo integrado que garante uma educação democrática e voltada para os interesses dos alunos. Sendo assim, mudanças curriculares envolvendo a inclusão de temas com apelo social não seriam suficientes para que se estabelecesse, no ambiente escolar, um compromisso com a formação de um cidadão crítico e 
Diferentes abordagens sobre o tema saúde ...

ativo na sociedade, pois, ao longo da história escolar, foram admitidos certos conhecimentos em detrimento de outros, e é este o ponto que precisa ser repensado. Vejamos o modo pelo qual estas mudanças se desenvolveram na prática.

\section{A inserção da Educação em Saúde (ES) na escola}

Tomamos como ponto de partida o final do século XIX e início do século XX, que, segundo diversos autores, é a época na qual se estabelecem mais fortemente e oficialmente as práticas de ES. O que marca fortemente esta época é o movimento denominado sanitarista, que apresentava como principal objetivo a higiene do corpo (biológica/cura) e da moral (comportamento). As práticas educativas em questão tinham como principal característica a normatividade e o autoritarismo. Estas eram movidas não apenas pelo interesse de criar ambientes saudáveis para os indivíduos, mas, sobretudo, pelo interesse político de controle e adequação da sociedade à estrutura burguesa.

Por meio das práticas sanitaristas e higienistas, a medicina se infiltra em toda a sociedade. São estabelecidas normas e condutas para a solução de problemas sociais e econômicos pautadas no conhecimento da clínica. Assim, a família, a infância, a escola e o trabalho ganham nova organização, influenciada diretamente pelo estabelecimento da ordem médica. A esse fenômeno de transformação social dá-se o nome de "medicalização" (COLLARES; MOISES 1985; LIMA, 1985; SPAZZIANI, 2001; SCHALL, 2005).

Segundo Lima (1985), o pensamento que norteia esta época, definindo o conceito de indivíduo, sociedade, saúde, família, enfim, é o da lógica de produção. Nesse sentido, a escola é lugar de adequação, que, de acordo com a classe, tinha um fim. Segundo Schall (2005, p. 46):

Os filhos das elites foram submetidos a uma educação higiênica, para disciplinar o espírito, reprimir e domar as más inclinações. [...] Os filhos de escravos mantiveram-se marginalizados da escola. Às crianças pobres só restava o ensino profissionalizante.

Tendo em vista que, no Brasil do século XIX, poucas crianças da classe popular frequentavam a escola, as práticas sanitaristas em nosso país eram executadas pela polícia sanitária (ASSIS, 1992), que estabelecia a ordem através da coerção, e não da educação, uma vez que esta não era para todos.

Com o desenvolvimento da medicina curativa, diminui drasticamente a situação de mortalidade, e a medicina toma como foco de estudos a prevenção. Surgem, a partir de então, outras maneiras de se entender, estudar e promover saúde. Ainda que timidamente, no início do século XX, o conceito de saúde deixa de ser apenas voltado para os aspectos biológicos do corpo devido à inclusão do meio ambiente como fator de controle da saúde. Em vista disso, as ações do governo se voltaram para a reestruturação arquitetônica das cidades, a fim de criar ambientes sadios. Foi, por exemplo, neste contexto, que a cidade do Rio de Janeiro foi totalmente revitalizada por meio da Reforma Pereira Passos.

Apesar de as ações deixarem de centralizar atenções apenas no corpo do indivíduo e se voltarem para os aspectos ambientais, o que permeava estas ações era a ideia de causa e 
efeito. Nesse sentido, manter o ambiente limpo viabiliza a manutenção da saúde humana. Essa preocupação tem ligação direta com as questões emergentes da época. $\mathrm{Na}$ ocasião, passávamos por problemas de natureza distinta dos que hoje afligem a sociedade e que nos levam a uma compreensão mais ampliada de meio ambiente, saúde e da relação entre os temas para além de causa e efeito.

De acordo com Collares e Moyses (1985), historicamente, a incorporação da saúde pela educação se dá através de dois caminhos: serviços de saúde escolar, vinculados às "pastas de educação", ou "programas de ensino da saúde", como, por exemplo, os Parâmetros Curriculares Nacionais. Segundo os mesmos autores, o primeiro caminho, em geral, se relaciona com práticas de controle higiênico do ambiente escolar e da inspeção da saúde física dos alunos. Estas são ações desenvolvidas por profissionais de saúde e possuem vinculação com o tradicionalismo higiênico. Já o segundo caminho, fica sob a responsabilidade dos professores, que, em geral, não recebem formação para atuar neste campo. Assim, “[...] esses programas são desenvolvidos, via de regra, com base no bom senso dos professores" (COLLARES; MOYSÉS, 1985, p. 14).

No Brasil, a Educação em Saúde se tornou oficial e obrigatória a partir da lei 5692/ 71, pela inserção dos Programas de Saúde (PS) nos currículos de primeiro e segundo graus:

Art. $7^{\circ}$ Será obrigatória a inclusão de Educação Moral e Cívica, Educação Física, Educação Artística e Programas de Saúde nos currículos plenos dos estabelecimentos de $1^{\circ}$ e $2^{\circ}$ graus, observado quanto à primeira o disposto no Decreto-Lei n. 369, de 12 de setembro de 1969. (BRASIL, 1971, p. 2)

Morh (2002), ao analisar o parecer 2.264/74 do Conselho Federal de Educação (CFE), que regulamentava a implementação dos PS, aponta aspectos positivos e negativos. Itemizando os achados da autora, podemos dizer que as orientações positivas, e até avançadas, do parecer são: o caráter interdisciplinar da proposta; a inclusão dos PS como responsabilidade de todas as disciplinas e atividades escolares, e a articulação da escola com os serviços públicos de saúde. Já os aspectos negativos dizem respeito: à não-consideração da realidade escolar e da formação disciplinar dos professores; à ênfase aos aspectos empíricos e menosprezo à teoria, e à valorização de uma educação comportamentalista, com excessiva ênfase no desenvolvimento de hábitos e atitudes, e bancária. A autora finaliza sua análise considerando que:

O parecer reduz os objetivos de uma atividade escolar desenvolvida ao longo de oito longos anos a alguns hábitos e atitudes e espera que, ao final de mais três, o aluno adquira apenas noções básicas sobre os fenômenos vitais. Sem dúvida, isto é subestimar, de forma inaceitável, o papel da escola na formação dos indivíduos. (MORH, 2002, p. 61)

Se o documento, apesar de negligenciar aspectos da realidade escolar, representou, em alguma medida, avanços no que diz respeito à ES na escola, o mesmo não pode ser considerado no âmbito da prática. De acordo com Mohr (2002), os PS, na prática, se restringiram à 
Diferentes abordagens sobre o tema saúde ...

criação de disciplinas, livros didáticos ou capítulos de livros, e pouco se relacionavam com as questões sociais da comunidade escolar.

Retomando a ideia trazida por Collares e Moysés (1985), podemos dizer que as práticas de ES se tornaram oficiais na escola brasileira via o que estes autores denominaram segundo caminho, e que, por consequência, a orientação do tema acabou sendo impactada pela falta de investimento na formação do professor e na articulação das ações desenvolvidas no âmbito do espaço escolar e entre este e outros espaços sociais.

Ao final da década de 1980, quando ainda vigoravam os PS, geralmente em forma de disciplina curricular, o debate no campo da saúde e educação em saúde já trazia perspectivas amplamente renovadas sobre o tema. No conceito ampliado, a saúde é tratada como fruto das condições de vida e trabalho da população, bem como de fatores sociais, econômicos, políticos, culturais, comportamentais e biológicos. Dentro deste pensamento, é formalizado o conceito de promoção da saúde na primeira conferência internacional sobre promoção da saúde em Ottawa, em1986 (PELICCIONI, 1995 apud PELICIONI, 2000).

Até o final da década de 1990, a disciplina "Programas de Saúde" manteve-se em vigor. Esta perdeu seu caráter de obrigatoriedade apenas em 1996, com a promulgação da nova lei de diretrizes e bases da educação, lei 9394/96 (SPAZZIANI, 2001). No entanto, com a formulação dos Parâmetros Curriculares Nacionais (PCN), em 1996, a saúde é novamente inserida de modo formal, embora não obrigatório, na Educação Básica. No documento em questão, o tema é tratado como tema transversal e passa a ser de responsabilidade de todas as disciplinas escolares. O documento também traz a perspectiva da integração deste tema com as questões ambientais e de educação sexual.

\section{A inserção da Educação Ambiental (EA) na escola}

Atualmente, e cada vez mais, são motivados desenvolvimentos de ações escolares que levem em conta a relação dos temas ambientais com a qualidade de vida do homem e do planeta. Tendo em vista que estas questões são mais recentes do que aquelas relacionadas à saúde, os temas ambientais começam a fazer parte da escola, numa perspectiva mais voltada para o social, somente ao final dos anos 1980.

À semelhança do que aconteceu com a inserção da educação em saúde na escola, a educação ambiental tem sua entrada via política oficial, mas sem que haja preparo dos professores. Dessa forma, o que ocorre é a orientação dos temas ambientais segundo aspectos ecológicos, muitas vezes restritos a questões técnicas de reciclagem e preservação.

Além disso, os temas relacionados ao meio ambiente entram na escola, via de regra, por meio das disciplinas ciências e biologia. Sendo assim, guardam forte relação com o saber de referência da ecologia e, em geral, os temas desta natureza entram como parte do conteúdo formal de ensino.

Exatamente no ano de 1988, a Educação Ambiental (EA) passa a ter caráter obrigatório por meio da nova Constituição Brasileira. A respeito da temática ambiental o documento destaca no Art. 225, no Capítulo VI - Do Meio Ambiente, Inciso VI, a necessidade de se "promover a Educação Ambiental em todos os níveis de ensino e a conscientização pública para a preservação do meio ambiente" (BRASIL, 1988, p. 3). Para cumprimento dos preceitos 
constitucionais, leis federais, decretos, constituições estaduais e leis municipais determinam a obrigatoriedade da Educação Ambiental.

No ano de 1999, é aprovada a lei 9.597/99, que estabelece a Política Nacional de EA, fortalecendo sua obrigatoriedade em todos os níveis de ensino. No mesmo ano, foi criada a Diretoria de Educação Ambiental do MMA Gabinete do Ministro, o Programa Nacional de Educação Ambiental e a Coordenação de EA do MEC, que passa a formar parte da Secretária de Ensino Fundamental (COEA).

Além da criação de leis e setores administrativos pela inserção da EA na escola, essa ideia também é reforçada nos Parâmetros Curriculares Nacionais. Assim como o tema saúde, o tema meio ambiente passa a fazer parte do grupo de temas transversais orientados pelo documento. Além de ser tratada como transversal, a questão ambiental também é aproximada dos temas relacionados à saúde e as orientações curriculares estimulam a abordagem dos temas de forma integrada.

O caráter de transversalidade, atribuído aos temas saúde e meio ambiente, traz uma nova perspectiva para o tratamento dos mesmos. Entretanto, uma breve leitura dos textos referentes aos temas transversais saúde e meio ambiente nos convida a pensar se, de fato, desde sua implantação, houve mudanças substanciais. Notamos que ainda persiste o discurso sobre o desenvolvimento de hábitos e atitudes e, em muitos casos, os textos parecem desconsiderar a realidade escolar. Sobre estes textos, Mohr (2002, p. 73) afirma que:

[...] os temas saúde e educação ambiental são concebidos como tendo uma meta única a saúde e a consciência ambiental. Estas são tratadas como se fossem entidades absolutas, não restando opção ao indivíduo (de bom senso e fruto de uma educação de qualidade) senão tentar atingi-las através de procedimentos-padrão.

Da mesma forma que vem ocorrendo ao longo dos anos em outros contextos de introdução de novas legislações ou recomendações curriculares na educação brasileira, os PCN invadiram o espaço escolar sem estarem associados a programas de formação continuada comprometidos com o debate sobre a orientação do trabalho com temas transversais ou sobre como trabalhar um enfoque interdisciplinar.

Em vista dos novos desafios que temos vivenciado em nosso cotidiano e compreendendo a amplitude das demandas colocadas para a escola, buscamos identificar em quais campos de conhecimento as discussões sobre a relação saúde - ambiente estão situadas. Essa imersão na literatura se justifica por acreditarmos na importância de compreender em quais campos discursivos o tema vem se consolidando, pois tais discursos, ao serem levados para a sala de aula, via trabalho docente, livro didático e projetos de setores governamentais ligados à educação, ao meio ambiente e à saúde, são novamente hibridizados com outros textos, outras perspectivas de mundo e se constituem, através de diversas influências, em textos originais dotados de características específicas daquele campo discursivo. Sendo assim, nosso mapeamento visa uma aproximação inicial a fim de compreender o contexto de produção original de tais discursos e inaugurar uma discussão sobre a entrada destes no campo educacional. 
Diferentes abordagens sobre o tema saúde ...

\section{A produção científica sobre o tema saúde e ambiente no Brasil}

A fim de compreender o cenário da produção científica sobre saúde e meio ambiente no Brasil, foi feita uma revisão de literatura a partir de consultas na base de dados Scielo. A escolha por esta base de dados se justifica pelo fato de sua abrangência de assunto ${ }^{3}$, a saber: Ciências Agrárias, Ciências Biológicas, Ciências da Saúde, Ciências Exatas e da Terra, Ciências Humanas, Ciências Sociais Aplicadas, Engenharias, Linguística, Letras e Artes.

As buscas foram realizadas por meio dos descritores "saúde" e "ambiente", usados de forma conjugada, e aplicada a todos os campos disponibilizados pela base de dados, que incluem resumo, palavras-chave, assunto, entre outros. Através deste mecanismo de busca, foram encontrados 732 artigos, que tiveram seus resumos e títulos lidos com a finalidade de selecionarmos aqueles que, de fato, dialogavam com o tema saúde e ambiente. Por meio desta leitura, selecionamos um total de trezentos e trinta artigos que claramente tratavam do tema.

De posse deste material, foi feita uma análise da frequência destas publicações nos periódicos, levando em consideração dois aspectos: (a) assunto/área temática/linha editorial da publicação; (b) formação/filiação institucional dos autores. Levando em consideração a classificação por assunto atribuída, aos periódicos, pela base de dados Scielo, verificamos a concentração quase total de publicações relevantes em periódicos identificados com as Ciências da Saúde (308 artigos) quando comparada à distribuição nas áreas de Ciências Agrárias, Ciências Biológicas, Ciências Humanas e Engenharias que, somadas, totalizavam apenas 22 artigos. Os artigos relacionados com as Ciências da Saúde foram classificados de acordo com a área temática/linha editorial da revista, segundo as seguintes categorias: Saúde, Saúde Pública, Saúde Coletiva, Epidemiologia e Enfermagem, o que permitiu constatar que, aproximadamente, a metade do total de trabalhos está vinculada à área da Saúde Pública (Gráfico 1).

Os artigos agrupados no item "outros", para melhor organização e apresentação dos dados, não formam um grupo homogêneo, pois são originados de revistas de Nutrição, Psicologia, Medicina Preventiva e Fonoaudiologia.

Gráfico 1. Distribuição dos artigos por subáreas da saúde

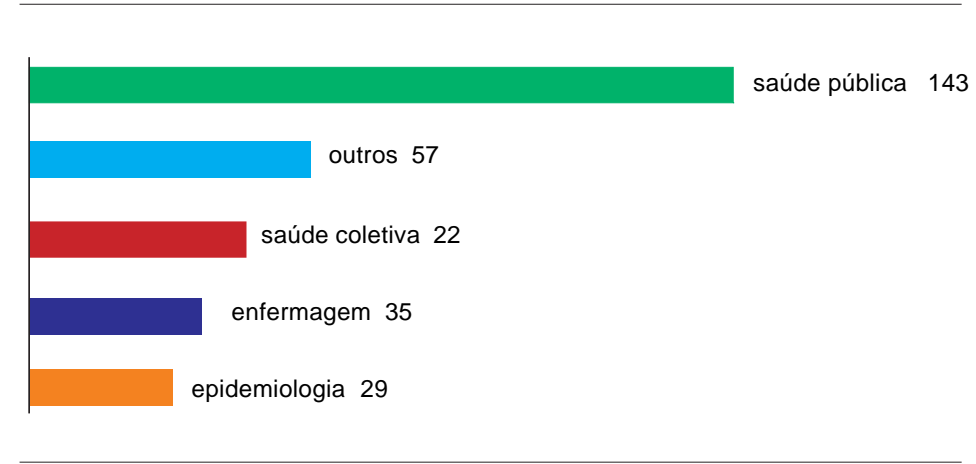

Fonte: Pinhão (2010, p. 44)

${ }^{3}$ Esta é a nomenclatura adotada na apresentação da base de dados. Disponível em: < http://www.scielo.org/ php/index.php>. Acesso em: 07 jun. 2009. 


\section{Pinhão, F.; Martins, I.}

Com relação à formação/filiação institucional do primeiro autor, percebemos que o padrão anterior é mantido, ou seja, a maioria deles é formada por ou vinculada a instituições ligadas às Ciências da Saúde.

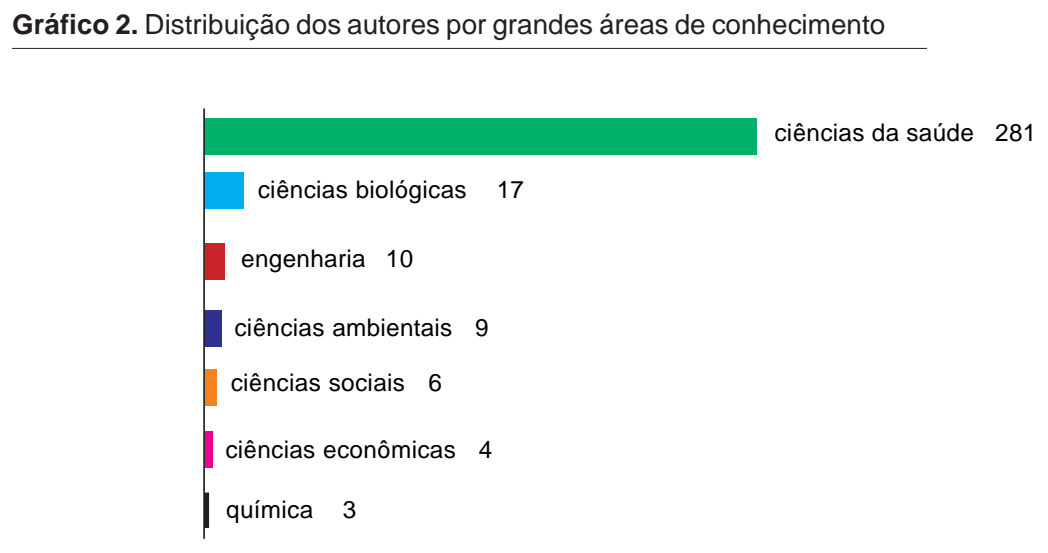

Fonte: Pinhão (2010, p. 44)

Tendo em vista o grande número de autores vinculados à grande área de conhecimento Saúde, foi feita uma classificação destes segundo a subárea específica da saúde onde atuam. Conforme demonstra o Gráfico 3, o padrão de distribuição dos dados de formação/ vínculo institucional dos autores é diferente daquele observado quando relacionamos autor à linha editorial da revista (Gráfico 1).

Gráfico 3. Distribuição dos autores por subáreas da saúde

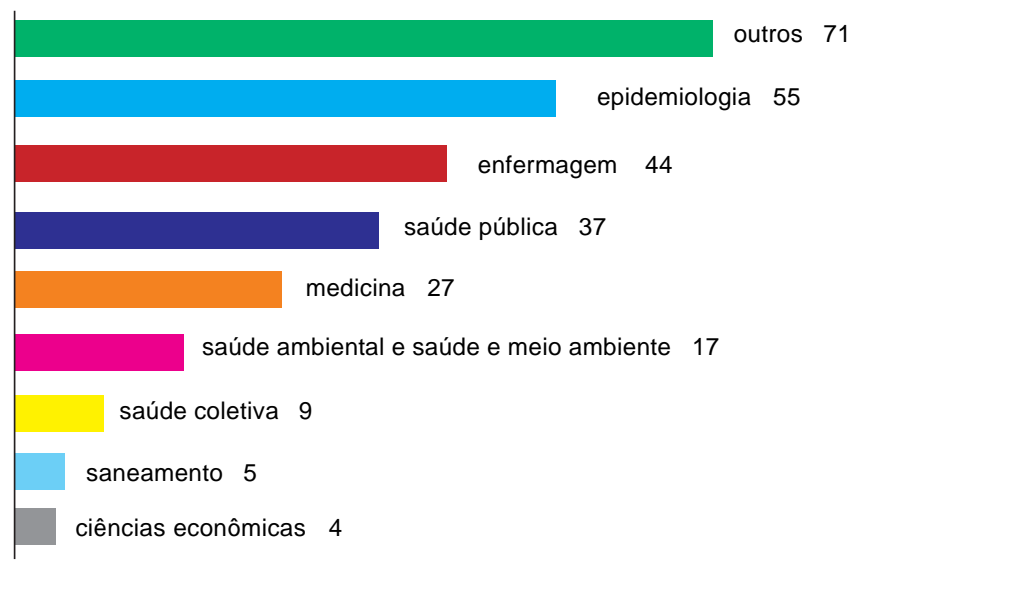

Fonte: Pinhão (2010, p. 45) 
Como pode ser visualizado no Gráfico 3, surgem três novas subáreas, que não aparecem quando o aspecto levado em consideração diz respeito à linha editorial da revista. Tal fato pode se justificar parcialmente pela inexistência de periódicos que tratem exclusivamente de ecologia humana, saneamento ou de questões que envolvam a temática saúde e ambiente, indexados na base de dados Scielo.

Em vista desta limitação do estudo, foi feita uma busca por periódicos que tratassem exclusivamente destes temas, e foi constatado que não existem publicações de âmbito nacional que sejam exclusivamente relacionadas com estas subáreas do conhecimento. Além disso, os departamentos e laboratórios que desenvolvem pesquisam com esta orientação são, em sua maioria, vinculados a instituições de Saúde Pública ou Saúde Coletiva. Tal fato se justifica pela própria história de constituição das subáreas que tratam especificamente de questões sobre ambiente e saúde.

Dentre o total de artigos (308), foram encontrados três artigos de revisão da área (CAMPONARA; KIRCHHOF; RAMOS, 2008; FREITAS, 2003, 2005). Este conjunto de artigos é formado por pesquisas recentes e de mesma natureza, que se complementam por elaborarem suas revisões de área a partir de recortes particulares. Nesse sentido, trazem informações que exploram o panorama nacional com base em uma diversidade de materiais, como artigos, teses, dissertações e dados de identificação de grupos de pesquisa, e, também, o panorama internacional, com base em artigos acadêmicos. Em vista da abrangência deste material e de sua atualidade, optamos por utilizá-los como base para nossa discussão.

Freitas (2003) elabora uma discussão sobre como aportes das Ciências Sociais são incorporados na produção do campo da Saúde Coletiva no Brasil. Para tanto, mapeou dados relativos à identificação de grupos de pesquisa e ao conteúdo de teses, dissertações e artigos que discutem relações entre saúde coletiva e problemática ambiental. A apresentação dos dados quantitativos demonstrou que, no ano de 2003, do total de grupos de pesquisa que continham o termo "ambiental" e "saúde" ou "saúde" e "ambiente" na sua identificação, apenas cinco, ou seja, $12 \%$ do total, se identificavam com as Ciências Sociais. Com relação às teses e dissertações produzidas entre os anos 1980 e 2000, o autor concluiu que 17 pesquisas, isto é, cerca de seis por cento do total, incluíam discussões vinculadas à área de Ciências Sociais. Já no levantamento de artigos, foram identificados apenas nove, ou seja, dez por cento do total, que versavam sobre temas e abordagens de interesse para as ciências sociais. Dentre estes, aproximadamente um terço tratava de questões vinculadas à educação. Freitas (2003) reforça o fato de que a relação entre os temas ocorre normalmente no contexto de uma discussão baseada em aspectos epidemiológicos e pouco relacionada a aspectos sociais. Além disso, aponta que, possivelmente, a pouca relação entre questões sociais, ambientais e de saúde reside na dicotomia entre o natural e o social.

Em outro artigo, Freitas (2005) analisa artigos nacionais publicados em periódicos identificados com as áreas de Saúde Pública, Saúde Coletiva e Epidemiologia. O período analisado, de 1992 a 2002, se justificou pelos marcos da Conferência RIO 92 - que, como dito anteriormente, configurou uma nova forma de se pensarem as questões ambientais para $O$ desenvolvimento sustentável, através da elaboração da Agenda 21 - e da realização da RIO+10 no ano de 2002, quando foi feito um balanço do desenvolvimento dos compromissos da Agenda 21 e se constataram poucos avanços em relação às metas por ela estabelecidas. A partir dos artigos selecionados, o autor analisa os problemas abordados com maior frequência, bem como 
Pinhão, F.; Martins, I.

as noções de saúde e ambiente neles encontradas. Dentre os problemas abordados com maior frequência nos artigos, estão: poluição, contaminação e intoxicação por produtos químicos no meio ambiente e seu potencial de impactos sobre a saúde, que correspondem a $28 \%$ do total. Outro grupo expressivo, que perfaz 19\% do total, inclui presença de vetores, hospedeiros e reservatórios no meio ambiente, e seu potencial de impactos sobre a saúde. Finalmente, cerca de 17\% dos trabalhos se referem a questões teóricas e metodológicas para a investigação e monitoramento dos problemas ambientais. Os três grupos correspondem a, aproximadamente, $64 \%$ do total de artigos encontrados. Tal dado demonstra a centralidade das questões relacionadas ao diagnóstico e mapeamento de agentes causadores de problemas de saúde presentes no ambiente. Outro aspecto discutido por este autor está relacionado com a conceituação predominantemente biologizada de saúde e ambiente. Tal ocorrência foi revelada pelo grande número de artigos, aproximadamente $85 \%$, que priorizavam a relação saúde-doença e aspectos biofísicos do ambiente. Artigos que buscavam a compreensão dos problemas por meio de aspectos multicausais, por exemplo, fazendo referência a aspectos relacionados ao contexto sócio-histórico, constituíram cerca de $25 \%$ do total de artigos. Segundo Freitas (2005), apesar das oportunidades de discussão proporcionadas pelas conferências e do apelo da Agenda 21 para um novo comportamento da comunidade científica na produção do conhecimento:

A produção sobre problemas relevantes, como estudos sobre políticas públicas, modelo de desenvolvimento e desigualdades sócio-ambientais e suas implicações para a sustentabilidade do ambiente e da saúde coletiva não só foi pouco expressiva quantitativamente, mas indica também a predominância de uma produção que qualitativamente pouco associa os problemas de saúde e ambiente às suas dimensões sociais, políticas e econômicas e que, orientada por noções de saúde e ambiente centradas nos aspectos biológicos e biofísicos tende a reduzir os mesmos a estes aspectos. (FREITAS, 2005, p. 13)

No trabalho desenvolvido por Camponara, Kirchhof e Ramos (2008), foram analisadas publicações nacionais e internacionais, como, também, a produção de teses e dissertações no âmbito nacional. O período analisado foi de 1993 até 2004. Em termos quantitativos, o Brasil aparece como o terceiro maior produtor de artigos sobre saúde-meio ambiente. Dentre o conjunto total das publicações, os três principais temas encontrados foram: exposição/ avaliação de risco relacionada à degradação ambiental e poluição; epidemiologia/controle de vetores; saúde pública e urbanização. Enquanto a primeira é mais frequente nas publicações de Estados Unidos e Rússia, a segunda é mais expressiva nos trabalhos realizados no Brasil e na Inglaterra. Este último padrão também é verificado nas teses e dissertações produzidas no Brasil, uma vez que um terço delas trata de epidemiologia/controle de vetores. Outro aspecto que diferencia a produção brasileira das demais é o número de publicações voltadas para a reflexão sobre políticas públicas e meio ambiente no contexto de discussões sobre qualidade de vida. Se, por um lado, Camponara, Kirchhof e Ramos (2008) qualificam este dado como relacionado a uma necessidade, por parte dos autores, de evidenciar uma lacuna no que se refere às políticas públicas, destacam, por outro, um possível impacto destas publicações no setor público. 
Diferentes abordagens sobre o tema saúde ...

Tomando por base as informações apresentadas nesta seção, assumimos que a produção sobre o tema saúde e ambiente apresenta-se mais identificada com a área da Saúde do que com os campos da Educação, da Ecologia Humana, da Ecologia e/ou de estudos sobre meio ambiente. Isto se justifica pelo fato de a discussão ser mais frequentemente encontrada em periódicos relacionados à área da Saúde, mesmo quando a pesquisa é produzida por autor vinculado a departamentos ou programas de pós-graduação de outras subáreas.

Embora os conceitos de meio ambiente e saúde não estejam, em sua origem, vinculados ao campo educacional, sua discussão é potencializada quando contextualizada nesse campo, gerando novas demandas tanto para o ensino escolar quanto para a educação não formal.

\section{Considerações finais}

Por meio dos dados obtidos no levantamento bibliográfico, bem como a análise de textos que fazem o estado da arte sobre o tema e os PCN, temos clareza de um cenário ainda em constituição e que se expressa na falta de pesquisas desenvolvidas de modo interdisciplinar. Os dados encontrados e discutidos em Camponara, Kirchhof e Ramos (2008) e Freitas (2003, 2005), demonstram que a abordagem contextual ainda é pouco tratada nas publicações nacionais e internacionais. Este fato pode ser atribuído à dificuldade de se desenvolverem trabalhos interdisciplinares e intersetoriais, como afirma Freitas (2005); como, também, ao fato de muitas pesquisas ainda serem desenvolvidas por meio de um modelo de investigação centrado apenas no problema e na consequência, como afirmam Camponara, Kirchhof e Ramos (2008). Estes dados também nos convidam a refletir sobre o próprio modo de produção científica, bem como a formação destes. Em geral, as graduações, em nível de bacharelado ou licenciatura mantêm currículos ultrapassados e fragmentados, prevalecendo um ensino pouco pautado na característica multidimensional dos problemas.

No cenário escolar não é diferente. O tema surge na escola de modo fragmentado, na medida em que os demais professores atribuem valor exclusivamente biológico ao atribuírem a responsabilidade do ensino de temas como saúde e ambiente ao professor de ciências. Infelizmente, nem os professores de ciências, nem seus colegas de outras disciplinas recebem, em sua formação inicial, subsídios que possibilitem a realização de um trabalho com estes temas que permitam ultrapassar a dimensão da transmissão de conteúdos básicos da ciência moderna, voltados apenas para aspectos morfológicos e funcionais. Por mais que, nas pesquisas, exista uma tendência de inclusão de abordagens mais complexas para as questões que relacionam saúde e ambiente, que valorize múltiplos fatores, na escola isto ainda não é comum.

Chamamos atenção para o fato de que estes conceitos básicos da ciência são, sim, fundamentais para compreendermos a relação saúde-ambiente. No entanto, um projeto educacional que vise à formação voltada para os problemas da vida real deve articular tais conhecimentos com aspectos da vida social, permitindo, ao aluno, conhecer não apenas os conceitos científicos, mas, também, as formas pelas quais estes medeiam a relação que estabelecemos com o mundo. Para tanto, abordagens interdisciplinares são fundamentais. 
Pinhão, F.; Martins, I.

\section{Agradecimento}

Trabalho realizado com apoio da CAPES/DS e do CNPq (Edital Ciências Humanas, 2006)

\section{Referências}

ASSIS, M. Da hipertensão à vida: por uma práxis comunicativa na educação e saúde. 1992. 165 f. Dissertação (Mestrado) - Instituto de Medicina Social, Universidade do Estado do Rio de Janeiro, Rio de Janeiro, 1992.

AUGUSTO, L. G. da S. et al. Saúde e ambiente: uma reflexão da Associação Brasileira de Pós-Graduação em Saúde Coletiva - Abrasco. Revista Brasileira de Epidemiologia, São Paulo, v. 6, n. 2, p. 87-94, 2003.

BRASIL. Lei $\mathrm{n}^{\circ}$ 5.692, de 11 de agosto de 1971. Fixa diretrizes e bases para o ensino de $1^{\circ}$ e $2^{\circ}$ graus, e dá outras providências. Diário Oficial da União, Brasília, 12 ago. 1971. Disponível em: < http://www.planalto.gov.br/ccivil_03/leis/15692.htm>. Acesso em: 12 set. 2012.

Constituição (1988). Constituição da República Federativa do Brasil de 1988.

Brasília, 1988. Disponível em: <http://www.planalto.gov.br/ccivil_03/constituicao/ constitui \%C3\%A7ao.htm>. Acesso em: 12 set. 2012.

Secretaria de Educação Fundamental. Parâmetros curriculares nacionais: apresentação dos temas transversais, ética. Brasília, 1997. Disponível em: <http:// portal.mec.gov.br/seb/arquivos/pdf/livro081.pdf>. Acesso em: 12 set. 2012.

Ministério da Saúde. Secretaria de Políticas de Saúde. A promoção da saúde no contexto escolar. Projeto Promoção da saúde. Revista de Saúde Pública, São Paulo, v. 36, n.4, p. 533-535, 2002.

BUSS, P. M. Promoção da saúde e qualidade de vida. Ciência \& Saúde Coletiva, Rio de Janeiro, v. 5, n. 1, p. 163-177, 2000.

CAMPONOGARA, S.; KIRCHHOF, A. L. C.; RAMOS, F. R. S. Uma revisão sistemática sobre a produção científica com ênfase na relação entre saúde e meio ambiente. Ciência $\boldsymbol{\&}$ Saúde Coletiva, Rio de Janeiro, v. 13, n. 2, p. 427-439, 2008.

COLLARES, C. A. L.; MOYSÉS, M. A. A. Educação ou saúde? Educação X saúde? Educação e saúde! Cadernos Cedes, Campinas, n. 15, p. 7-16, 1985.

FOUREZ, G. A construção das ciências: introdução à filosofia e à ética das ciências. São Paulo: UNESP, 1995. 
Diferentes abordagens sobre o tema saúde ...

FREITAS, C. M. Problemas ambientais, saúde coletiva e ciências sociais. Ciência \& Saúde Coletiva, Rio de Janeiro, v. 8, n. 1, p. 137-150, 2003.

A produção científica sobre o ambiente na saúde coletiva. Cadernos de Saúde Pública, Rio de Janeiro, v. 21, n. 3, p. 670-201, maio-jun. 2005.

FREITAS, C. M. et al. Ecosystem approaches and health in Latin America. Cadernos de Saude Publica, Rio de Janeiro, v. 23, n. 2, p. 283-296, 2007.

FREITAS, C. M.; PORTO, M. F. de S. Saúde, ambiente e sustentabilidade. Rio de Janeiro: Editora FIOCRUZ, 2006.

LIMA, G. Z. Saúde escolar e educação. São Paulo: Cortez, 1985.

LOPES, A. C. Reflexões sobre a epistemologia da disciplina escolar ciências. Educação em Foco, Juiz de Fora, v. 5, n. 1, p. 55-64, 2000.

LOPES, A. R. C. A integração curricular em textos de ciências para o ensino médio. Rio de Janeiro: UERJ, 2002. (Projeto integrado de pesquisa). Disponível em: $<$ http://www. curriculo-uerj.pro.br/docs/a_integracao_curricular_em_textos_de_ciencias_para_O_ ensino_medio.pdf>. Acesso em: 01 jul. 2008.

MACEDO, E. F. de. Os temas transversais nos parâmetros curriculares nacionais. Química Nova na Escola, São Paulo, n. 8, nov. 1998.

MACEDO, E.; LOPES, A. C. A estabilidade do currículo disciplinar: o caso de ciências. In: . (Org.). Disciplinas e integração curricular: história e políticas. Rio de Janeiro:

DP\&A, 2002. p. 73-94.

MINAYO, M. C. S. et al. Fiocruz saudável: uma experiência institucional. Ciência \& Saúde Coletiva, Rio de Janeiro, v. 3, n. 2, p. 151-161, 1998.

MORH, A. A natureza da educação em saúde no ensino fundamental e os professores de ciências. 2002. 409 f. Tese (Doutorado em Educação) - Centro de Ciências da Educação, Universidade Federal de Santa Catarina, 2002.

PELICIONI, M. C. F. Educação em saúde e educação ambiental: estratégias de construção da escola promotora da saúde. 2000. 185 f. Tese (Livre-docência em Saúde Pública) - Faculdade de Saúde Pública, Universidade de São Paulo, São Paulo, 2000.

PIGNATTI, M. G. Saúde e ambiente: as doenças emergentes no Brasil. Ambiente \& Sociedade, Campinas, v. 7, n. 1, p. 133-147, jan./jun. 2003.

PINHÃO, F. L. O tema saúde e ambiente no livro didático de ciências: uma abordagem discursiva. 2010. 132 f. Dissertação (Mestrado em Educação em Ciências e Saúde) - Universidade Federal do Rio de Janeiro, Rio de Janeiro, 2010.

RIBEIRO, H. Saúde pública e meio ambiente: evolução do conhecimento e da prática, alguns aspectos éticos. Saúde e Sociedade, São Paulo, v. 13, n. 1, p. 70-80, jan.-abr. 2004.

SCHALL, V. Educação em saúde no contexto brasileiro: influências sócio-históricas e tendências atuais. Educação em Foco, Belo Horizonte, v. 1, n. 1, p. 41-58, dez./mar., 2005. 
Pinhão, F.; Martins, I.

SPAZZIANI, M. A saúde na escola: da medicalizacão à perspectiva da psicologia histórico-cultural. Educação Temática Digital, Campinas, v. 3, n. 1, p. 41-62, dez. 2001.

TAMBELLINI, A. T.; CÂMARA, V. M. A temática saúde e ambiente no processo de desenvolvimento do campo da saúde coletiva: aspectos históricos, conceituais e metodológicos. Ciência e Saúde Coletiva, Rio de Janeiro, v. 3, n. 2, p. 47-59, 1998.

Artigo recebido em 21/10/2011. Aceito em 04/07/2012. 